\title{
ANTIOBESITY ACTIVITITY OF WATER FRACTIONS EXTRACT OF TAMARIND (TAMARINDUS INDICA L.) IN HIGH CARBOHYDRATE DIET INDUCED MALE WISTAR RATS
}

\author{
NURUL HIDAYAH ${ }^{1}$, KETUT ADNYANA I ${ }^{2 *}$, NENG FISHERI $^{2}$, FINNA SETIAWAN ${ }^{3}$ \\ ${ }^{1}$ Departement of Pharmacology and Toxicology, Faculty of Pharmacy, Polytechnic Health of Medan, Medan, Indonesia. ${ }^{2}$ Departement of \\ Pharmacology and Toxicology, School of Pharmacy, Bandung Institute of Technology, Bandung, Indonesia. ${ }^{3}$ Departement of Pharmacology \\ and Toxicology, University of Surabaya, Surabaya, Indonesia. Email: ketut@fa.itb.ac.id
}

Received: 07 March 2018, Revised and Accepted:25 March 2018

ABSTRACT

Objective: The prevalence of obesity increases each year globally. Multifactorial etiology of obesity requires therapy management including changing of diet and medicines. Some of obesity drugs have shown ineffectiveness and safety. The previous study showed that water extract of tamarind could reduce body weight (bw). This study aimed to test the activity fraction of water extract tamarind as antiobesity using high carbohydrate diet.

Method: The preventive research of antiobesity had done by given water fraction and ethyl acetate fraction of water extract tamarind following with induced high carbohydrate diet during $6^{\text {th }}$ weeks in male Wistar rats. The parameters had observed including consumption of food, body weight, weight of feces, volume of urine, total cholesterols, triglycerides, blood glucose, index of organs, and accumulation of body fat.

Result: The ethyl acetate fraction at doses $4.5 \mathrm{mg} / \mathrm{kg}$ bw has shown significantly effect to decrease of total cholesterols level and decrease of triglycerides level at weeks $6(\mathrm{p}<0.05)$. All the tests of fraction have shown activity inhibition of increased body weight, decrease of appetite, total cholesterols, triglycerides, and blood glucose. Meanwhile, mechanism action of antiobesity as increase defecation, urination, and decrease index of organs and accumulation of body fat have not shown by all these test fractions.

Conclusion: The ethyl acetate fraction at doses of $4.5 \mathrm{mg} / \mathrm{kg}$ bw can inhibit raising of body weight, decrease of total cholesterols, and triglycerides level greater than the other test groups, where increasing of these levels of blood biochemistry was closely related to the pathology of obesity.

Keywords: Antiobesity, Fraction of water extract tamarind, High carbohydrate diet.

(C) 2018The Authors. Published by Innovare Academic Sciences PvtLtd. This is an open accessarticle under the CC BY license (http://creativecommons. org/licenses/by/4. 0/) DOI: http://dx.doi.org/10.22159/ajpcr.2018.v11s1.26606

\section{INTRODUCTION}

Obesity is a condition which imbalance between intake energy and output energy. Obesity and overweight had been a correlation with the high risk of developing disease, low of the outcomes patient, and high of cost [1]. The prevalence of obesity had been global problems. At 2015 estimate, 2.3 billion of society was to be overweight and 700 million patient was to be obese [2]

Multifactorial etiology of obesity requires therapy management which includes changing of diet, behavior, physical activity, medicine, and drugs [1]. Currently, some of the antiobesity drugs were approved, but the regimen of long duration therapy has been ineffective, which about $90 \%-95 \%$ patients decreased body weight to be obese again. In the other sides, antiobesity drugs also have shown safety problems and addictivity [3]. Based on those condition, there was an alternative therapy to treat obesity effectively[4]

The treatment of obesity and related of profile lipid using medicinal plants has increased in recent years. Herbal medicine as one of the traditional therapies had been use in the world because trusted that more safety than modern medicine. One of the medicinal plants was screening to the treatment of that disease is Tamarindus indica L. Result of phytochemistry screening of this plants has shown that tamarind contains phenolic compounds such as catechin, procyanidin B2, epicatechin, tartrate acid, mucilage, pectin, arabinosa, xilosa, uronat acid, and triterpene [5]. Previous studies have shown that water extract of tamarind could inhibit enzyme pancreatic lipase, increase of body weight, influence of lipid profile, increase of blood glucose level, and risk of resistance insulin [4,6-11].

Therefore, the aim of this research was to investigate the effect of fractions of water extract tamarind as antiobesity in male Wistar rats with high carbohydrate diet induced. The model of induction was obtained from the previous studies which showed that high carbohydrate diet has obtained the higher result of an increase of body weight in male $[6,7,12]$. On the other hand, this model induced appropriate with the pattern diet in developing country like Indonesia, which uses carbohydrate diet as source of energy. This research will observe the mechanism of action of fractions from water extract tamarind as antiobesity includes body weight, consumption of food, volume of urine, weight of feces, blood glucose level, triglycerides level, total cholesterols level, resistance insulin, index of organs, and index of body fat accumulation.

\section{METHODS}

Extraction

Early-stage research method is preparation of fresh material of tamarind.

\section{Plant material and identification}

Tamarind was collected from Lembang, Bandung and the material was indentified by Herbarium Bandungense School of Sains and Biological Technology - Institute Technology of Bandung (ITB).

\section{Animals}

Adults male Wistar rats aged 8-12 weeks, weighing about 150-180 g, healthy with normal activity were obtained from the Laboratory of Pharmacology and Toxicology, School of Pharmacy Institute of Technology, Bandung. The treatment was given according to ethics for the care and use of laboratory animal.

Chemical

Destilled water, high carbohydrate diet, acarbose was obtained from Bayer Schering Pharma, glucose reagent kit, triglyceride reagent kit, 
and cholesterol reagent kit. All other chemical reagents were analytical grades.

\section{Preparation of plant extract}

Fresh pulp was collected by peeled the tamarind fruits, separated from the seed, and extracted with water by refluxing for $2.5 \mathrm{~h}$. The refluxate was concentrated by freeze drying. After that, the extract was fractionated by liquid-liquid fractionation with n-hexane, ethyl acetate, and water, respectively.

\section{Phytochemical screening and characterization of extract}

Phytochemical screening to indentified metabolite secondary was implicit of the extract qualitatively. Phytochemical screening includes alkaloids, flavonoids, saponins, tannins, and steroid/triterpenoid. Extracts' characterization includes determination of total ash level, ash of insoluble acid level, specific gravity, drying shrinkage, extracts of soluble water level, and extracts of soluble ethanol level.

\section{Experimental design}

After acclimatized, the test animals will be divided into seven groups. Normal group had given the standard feed which obtained from Pharmacology Laboratory of ITB following given carrier solvent only, whereas the other groups had given high carbohydrate diet. The Negative control group has given solvent only, the compare group has given acarbose at dose of $4.5 \mathrm{mg} / \mathrm{Kg}$ bw and treatment group was divided into four groups consist of ethyl acetate fraction at doses of $2.25 \mathrm{mg} / \mathrm{Kg}$ bw and $4.5 \mathrm{mg} / \mathrm{Kg} \mathrm{bw}$, and for water fraction at dose of 65 $\mathrm{mg} / \mathrm{Kg}$ bw, and $130 \mathrm{mg} / \mathrm{kg}$ bw, respectively. All the treatment had given during 6 weeks. Parameters were observed including body weight, consumption of diet, volume of urine, weight of feces, blood glucose level, triglycerides level, total cholesterols level, and organ index and body fat accumulation. Furthermore, results were processed using Microsoft Excel and SPSS version 20.0 statistically showed that there is not significant difference between all the group test.

\section{RESULT}

Extract was proceeded by reflux method using aquadest as a solvent and freezed drier to get dried extract. Result of extraction was obtained about $32.13 \%$. After that, water extract was fractionated by extraction liquid-liquid use n-hexane (for nonpolar fraction), ethyl acetate (for semi polar fraction), and water (for polar fraction). The Percentage of weight of these fractions, respectively, was obtained about $0.04 \%$, $2.94 \%$, and $88.14 \%$.

Phytochemical screening and characterization of extract

Phytochemistry screening of water extract of tamarind (T. indica L.) showed the positive of flavonoid, saponin, and tannin. Water extract of tamarind was characterized includes extracts of solute water level, extracts of solute ethanol, total ash level, ash not solute in acid, and Shrunk to drying (Table 1).

Effect antiobesity of fraction of water extract tamarind to parameter research

\section{Consumption of diet}

Fig. 1 showed that induction group has consumption of diet tend increase than acarbose group and all the fraction group test, which the increasing begin from at week 3 up to weeks 6 . However, analysis of statistic $(\mathrm{p}<0.05)$ showed no significant effect between all group in case total consumption of diet.

\section{Body weight}

Fig. 2 shows that induction group has a presentation of increased body weight highest than the other groups. Ethyl acetate fraction at doses $4.5 \mathrm{mg} / \mathrm{kg}$ body weight has the presentation of inhibition body weight highest than the other groups, which this effect begins at 21day therapy until the end of this research. According to the analyses of statistic showed that no significant difference between group for this parameter $(\mathrm{p}<0.05)$.
Table 1: Characteristics of water extract of tamarind (T. indica L.)

\begin{tabular}{ll}
\hline Parameters & Result \\
\hline Rho 1\% (mg/ml) & 1.11 \\
Extract of solute water level $(\% \mathrm{w} / \mathrm{w})$ & 80.12 \\
Extract of solute ethanol level $(\% \mathrm{w} / \mathrm{w})$ & 56.41 \\
Total ash level $(\% \mathrm{w} / \mathrm{w})$ & 7.12 \\
Level of ash not solute in acid solvent $(\% \mathrm{w} / \mathrm{w})$ & 0.81 \\
Shrunk to dry $(\% \mathrm{w} / \mathrm{w})$ & 17.83 \\
\hline
\end{tabular}

T. indica: Tamarindus indica

\section{Volume of urine}

Fig. 3 shows that normal group has volume of urine highest than the other groups at all weeks. Acarbose group and water fraction at doses $130 \mathrm{mg} /$ $\mathrm{kg}$ body weight showed the increasing volume of urine from 0 week until weeks 6 ; meanwhile, the other groups have unstable of pattern.

\section{Weight of feces}

Fig. 4 shows that ethyl acetate fraction has the increased presentation weight of feces than the other groups at doses $2.25 \mathrm{mg} / \mathrm{kg}$ body weight begins at weeks 3 but decrease at weeks 6 . On the other hand, ethyl acetate at doses $4.5 \mathrm{mg} / \mathrm{kg}$ body weight has increased presentation begin at week 0 until 6 . The other groups showed unstable pattern. Analyzes statistic was obtained no significant difference between all the group test.

\section{Triglycerides level}

Fig. 5 showed that induction group was present the highest change of triglycerides' level than the other groups. Water fraction group has the presence of increased triglycerides' level highest at weeks 3 than the others groups but decreased at weeks 6 . This happens was estimated that this fraction gave effective to decrease triglycerides level at week 6 of the therapy. According to analyzes of statistic was obtained a result that no significant different between all group at weeks 3 , meanwhile at weeks 6 have significantly different $(p<0.05)$.

\section{Total cholesterols level}

Fig. 6 shows that induction group has presentation of increased total cholesterol level highest during research that the other groups. Based on the statistical analyzes at weeks 3 , the obtained a result showed that has significant difference in all the group test to induction group, meanwhile at weeks 6 showed significant different between ethyl acetate group at dose of $4.5 \mathrm{mg} / \mathrm{kg}$ body weight and normal group to induction group $(\mathrm{p}<0.05)$.

\section{Blood glucose level}

Fig. 7 shows that induction group has presentation of increased blood glucose level highest than the other groups during therapy. Meanwhile, water fraction at doses $65 \mathrm{mg} / \mathrm{kg}$ body weight showed increase of presentation of blood glucose level at weeks 3 and decreased at weeks 6 .

\section{Index of organs and index of body fat accumulation}

Based on Fig. 8 shows that the group has an index of liver acarbose highest compared with other groups; meanwhile the water fraction group at doses $65 \mathrm{mg} / \mathrm{Kg}$ bw has an index of renal fat and fat anal biggest compared with other test groups. Statistical analysis showed no significant differences in cardiac index, heart, renal fat, and fat anal among all groups.

\section{DISCUSSION}

Consumption of diet correlated with appetite in models induced animals. Fig. 1 shows that induction group has consumption of diet tend increase than acarbose group and all the fraction group tests. Result of this research accordance with the extract tamarind can decrease the consumption of diet not significantly. One of the etiologies of obesity is eating behavior or diet. Control of food intake involves a biochemical process that determines hunger and satiety including the determination of the type of food tastes, appetite, and food frequency. Large and 


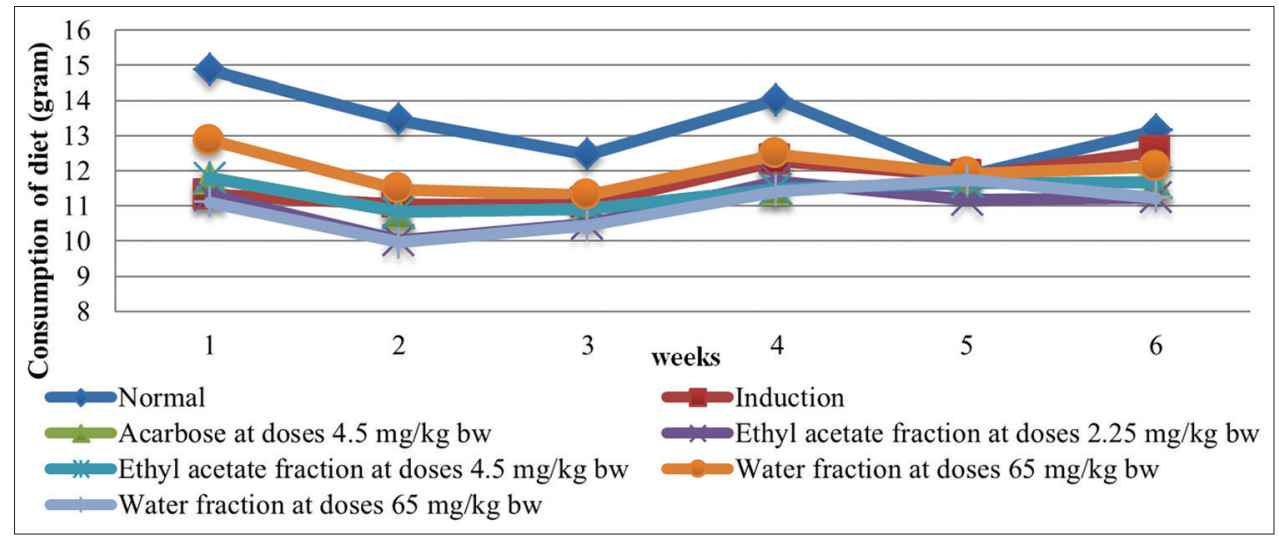

Fig. 1: Consumption of diet weekly all animal group test

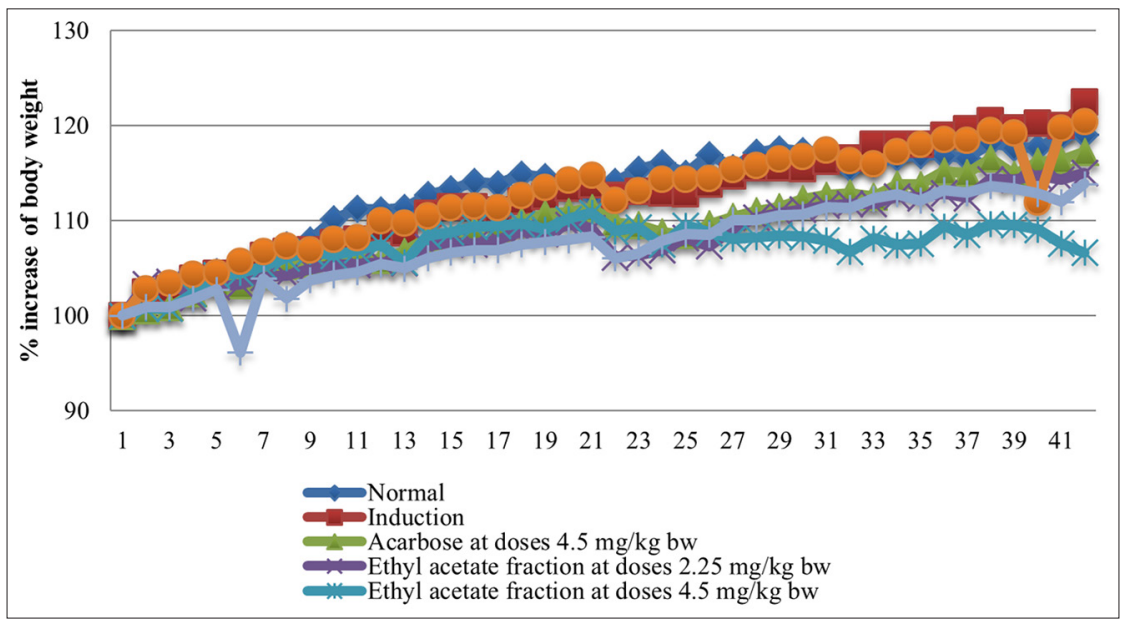

Fig. 2: Presentation of increase body weight daily all group animal test

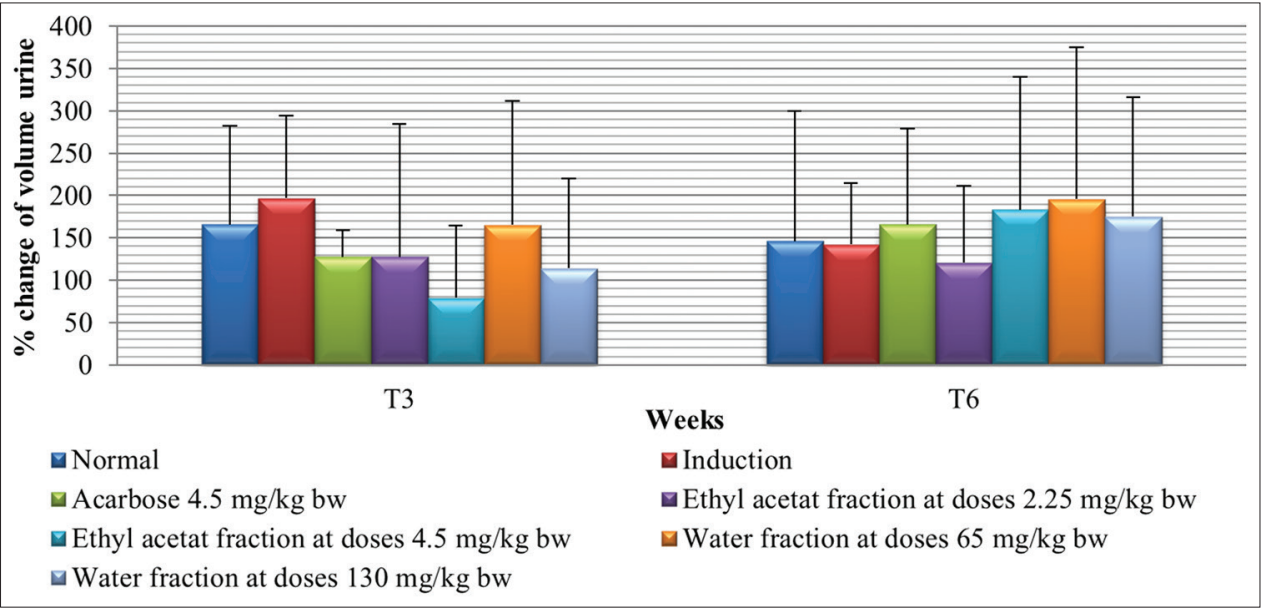

Fig. 3: Presentation of change volume of urine all group animal test to T0

energy storage activity, particularly in fat tissue, communicated to the central nervous system through the mediator of leptin and other signal transduction. Leptin is an important regulator in the energy balance of the body. Leptin is secreted adipocytes into circulation and transported to the central nervous system to bind to leptin receptors in the nucleus of the hypothalamus aquartus. This bond stimulates the synthesis of pro-opiomelanocortin (POMC) [13].

Furthermore, POMC will produce alpha-melanocyte-stimulating hormone $(\alpha-\mathrm{MSH})$ and adrenocorticotrophine. $\alpha$-MSH will bind to the receptor and give the effect satiety. Mutations of genes encoding leptin (leptin, POMC, and melanocortin 4 receptor), and signal transduction (signal hunger and satiety) will affect the control of food intake and lead to the onset of obesity [13].

Fig. 2 shows that induction group has a presentation of increased body weight highest than the others groups. The result showed that the induction model has potential to increase body weight although the total food consumption is smaller than normal group. Result of this research in line with the previous research, Which is induction group 


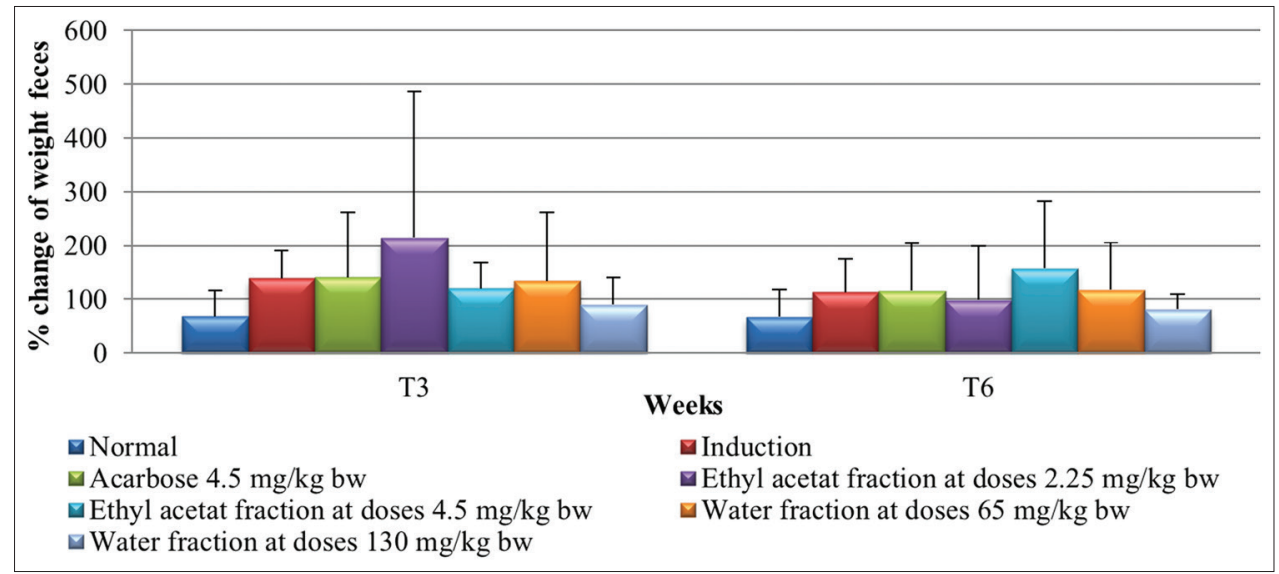

Fig. 4. Presentation of change weight of feces all group animal test to T0

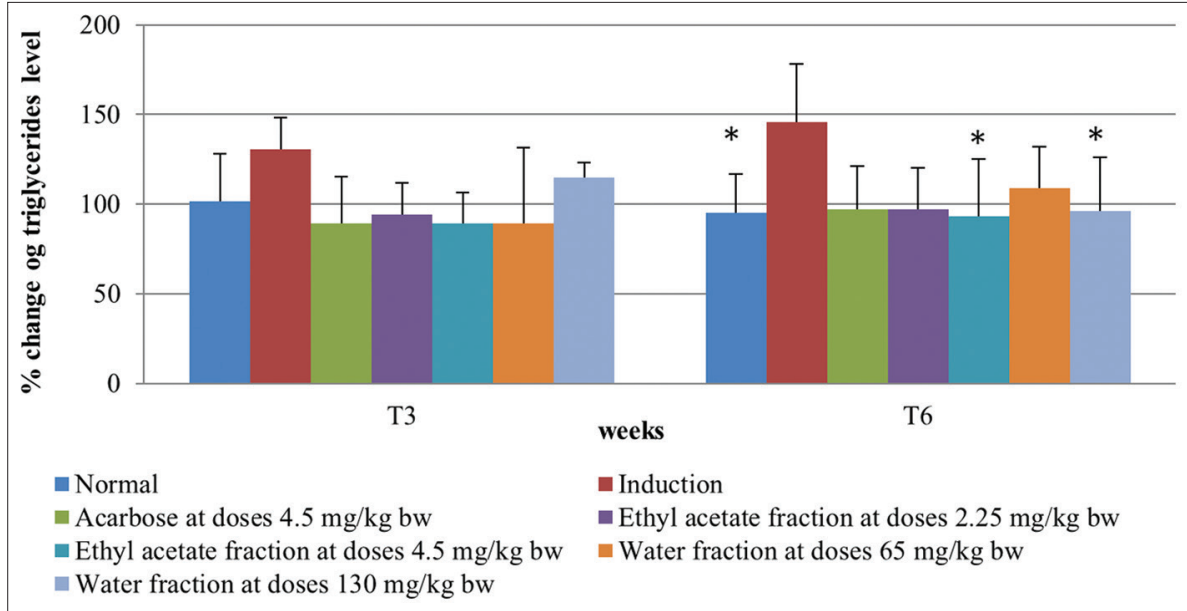

Fig. 5: Presentation of change triglycerides level all animal test to T0. *significant different to induction group (p<0.05)

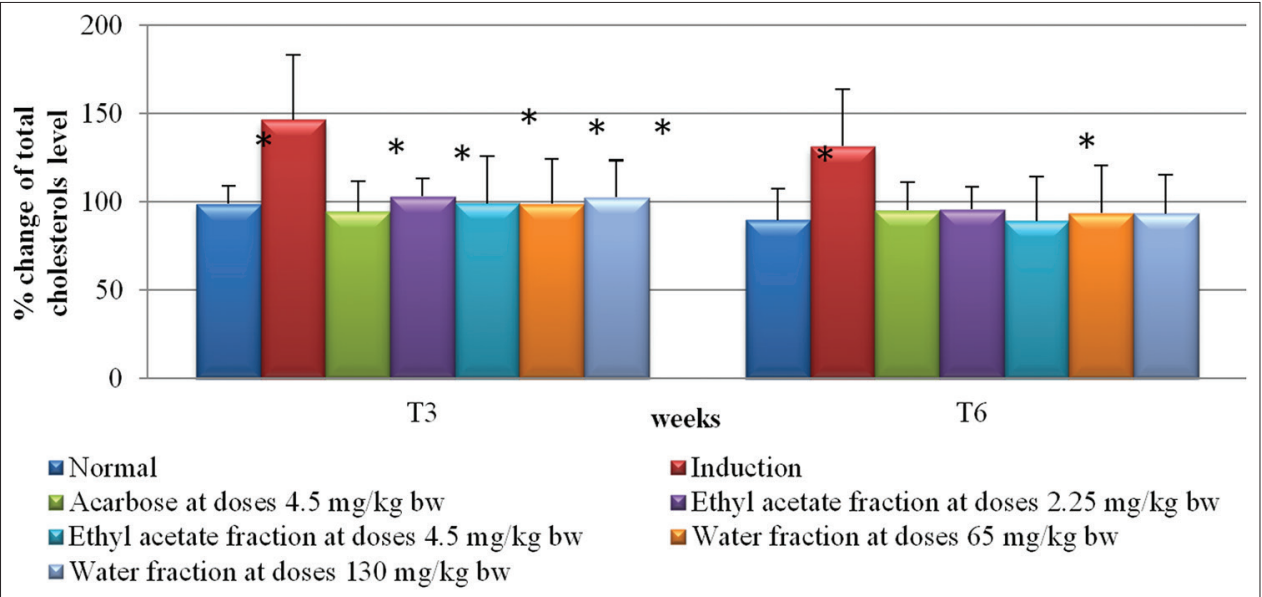

Fig. 6: Presentation of change total cholesterols level all animal test to T0. *significant different to induction group (p<0.05)

with high carbohydrate diet showed the highest body weight rather than the others group [14]. The previous studies showed that water extract of tamarind during 3 months inhibited of increased body weight at doses $75 \mathrm{mg} / \mathrm{kg}$ bw than at doses $225 \mathrm{mg} / \mathrm{kg}$ body weight, which this effect begins at weeks 3 of the research for the preventive method and weeks 9 for the curative method [7].

Ethyl acetate fraction at doses $4.5 \mathrm{mg} / \mathrm{kg}$ body weight has the presentation of inhibition body weight highest than the others groups, which this effect begins at 21-day therapy until end of this research. According to the statistical analyses showed that no significant difference between group for this parameter $(p<0.05)$.

High-fat diet knows as one of the causal factor that increasing the prevalence obesity in the world. This case makes the other ways to cover require of the intake energy with high carbohydrate diet. The changing of the model diet from high-fat diet to high carbohydrate diet al.o makes the population of obese increase in each year in the USA 


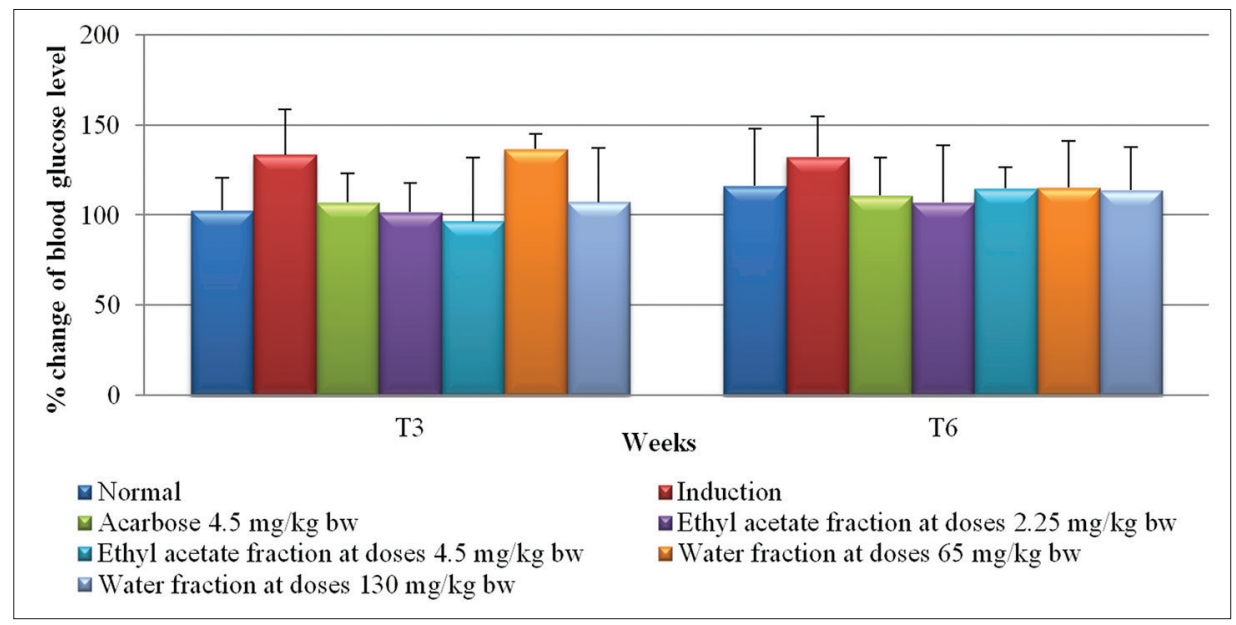

Fig. 7: Presentation of change blood glucose level all animal groups to T0

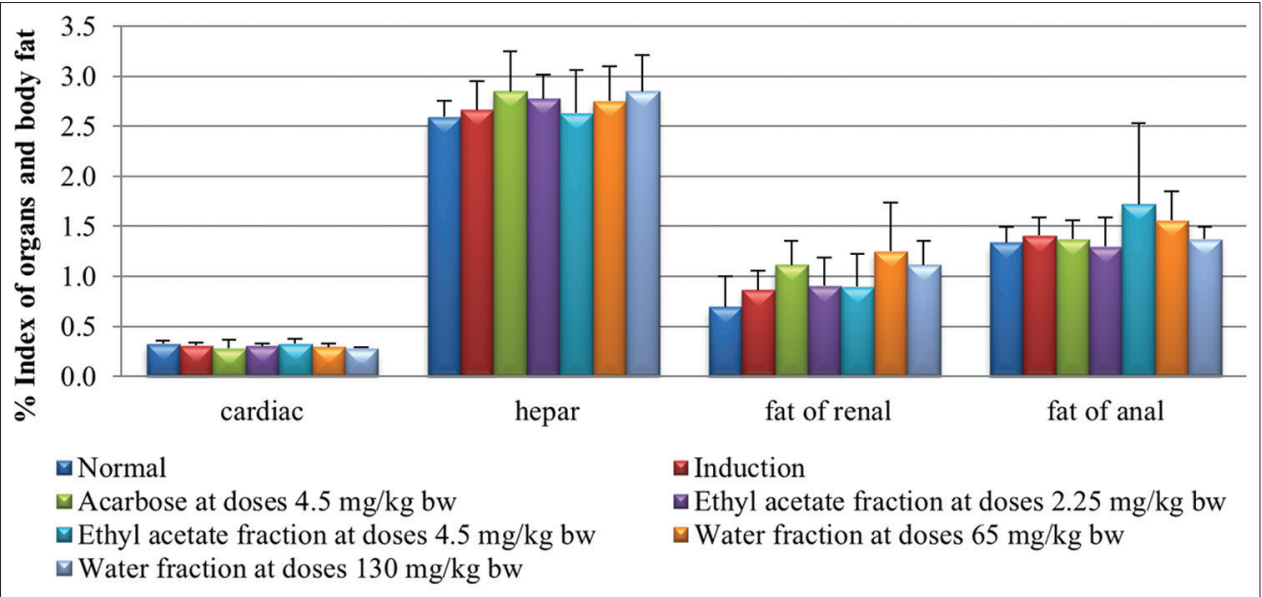

Fig. 8: Presentation of organ index and accumulation of body fat

[15]. The previous study showed that the high carbohydrate diet can increase the animal weight in obesity model research. This effect could correlate with the quality of consumption of carbohydrate (glycemic index and glycemic load), which believe give the significant contribution on the increase of body weight and high of cardiovascular case $[15,16]$.

Based on this result, assumed that all the fraction test could have not activity as diuretics as one of the mechanism action inhibition of increase body weight. Based on this result, assumed that the fraction test have no activity as lacsative.

According to the Fig. 6, showed that induction group have highest presentation of change triglyceride level than the others group. The previous studies showed that high carbohydrate diet could increase triglycerides level than low-fat diet $[17,18]$. Starches, sugars (especially sucrose and fructose) tend to increasing triglyceride level up to $60 \%$, which the amount of increase depends on some aspect diet, such as the amount of consumption carbohydrate, kind of fat, and consumption of fiber [16].

Water fraction group have the presentation of increase triglycerides level highest at weeks 3 than the others group but decrease at weeks 6 . This happens was estimated that this fraction gave effective to decrease triglycerides level at week 6 of the therapy. Previous studies also showed the same effect with this research, that induction group have the triglycerides level highest than the others group. Water extract of tamarind at doses $225 \mathrm{mg} / \mathrm{kg}$ body weight have smallest of triglycerides level in the end of the therapy, which the decrease of triglycerides level begin at weeks 3 in preventive method, and weeks 9 in curative method [7]. According to analyzes of statistic was obtained result that no significant different between all group at weeks 3, meanwhile at weeks 6 have significant different $(\mathrm{p}<0.05)$.

Straches,fructose, quicklytransportedtotheliver,whereitwillbeconverted into glycerol-3-phosphate, undergoesterificationwithfattyacidsto form triglycerides. Furthermore, triglycerides are coated with apolipoproteinB (apoB) and secreted into plasma as very low-density lipoprotein (VLDL). The rate of lipolysis of visceral fat depot may also increase the availability of fatty acids and promote hepatic triglyceride synthesis.Triglycerides are normally cleared by lipoprotein lipase. A diet high in sugar can modify the rate of clearance of circulating triglycerides. Because a diet high in sugar can increase VLDL, these particles will compete to be hydrolyzed by lipoproteinlipase, thereby delaying the clearance silomycronandthe amountat the time offasting. The higheraffinity of lipoproteinlipaseVLDLwas comparedto silomycronalso factors that determine the relationshipclearance oftriglycerides inlipoproteinfractions [16].

Based on Fig. 7 shows that induction group has a presentation of increased total cholesterol level highest during research that the other groups. According to statistical analysis at weeks 3, the result showed that the significant difference of all groups test to induction group, meanwhile, at weeks 6 showed significant differences between ethyl acetate group at doses of $4.5 \mathrm{mg} / \mathrm{kg}$ body weight and normal group to induction group $(\mathrm{p}<0.05)$. The previous studies showed that water extract of tamarind at doses $75 \mathrm{mg} / \mathrm{kg}$ body weight has total 
cholesterols level lower than induction group, which this effect begin at weeks 3 of the therapy [7].

After the process of absorption through the intestinal wall, most of the monosaccharide was carried by the bloodstream to the liver. In the heart, monosaccharides undergo a process synthesis to produce glycogen, oxidation to $\mathrm{CO}_{2}$ and $\mathrm{H}_{2} \mathrm{O}$, or release to carry the blood flow to parts of the body that need. Most of the monosaccharides were taken directly to a specific organ, and tissue cells undergo metabolic processes further. Blood glucose levels increase as a result of the increase in the process of digestion and absorption of carbohydrates, glycogen synthesis of glucose by the liver to rise. High glucose levels will further stimulate the formation of glycogen from glucose, fatty acid synthesis, and cholesterol from glucose [19].

Complex plasma lipids (triglycerides, cholesterol, phospholipids, and free fatty acids) and apolipoprotein forming lipoprotein that is soluble in water. Because all lipoproteins containing plasma lipid, the increasing of triglycerides level can also affected the increase of total cholesterol level.Triglycerides and cholesterols are synthesized by the liver and transported in the form of VLDL, to further undergo hydrolysis by lipoprotein lipase into smaller particles that intermediate density lipoprotein and LDL. LDL is a lipoprotein cholesterol containing at most (60-70\%). Cholesterols are also synthesized from acetate path under the influence of the enzyme HMG-CoA reductase that becomes active if there is a shortage of endogenous cholesterol. The intake of cholesterols from the blood is also governed by the number of LDL receptors on the surface of liver cells. In patients with hypercholesterolemia, catabolism by the liver and peripheral tissues is reduced so that increased plasma cholesterol levels. Increased cholesterol levels partly channeled into macrophages that play a role in the occurrence of premature atherosclerosis [20].

Induction group has a presentation of increased blood glucose level highest than the other groups during therapy. Meanwhile, water fraction at doses $65 \mathrm{mg} / \mathrm{kg}$ body weight showed an increase of presentation of blood glucose level at weeks 3 and decreased at weeks 6 (Fig. 8). Previous studies showed that induction group has blood glucose level highest compare the others group. Meanwhile, water extract of tamarind at doses $75 \mathrm{mg} / \mathrm{kg}$ body weight gave the effect of decreased blood glucose level at weeks 9 [7].

According to result of statistical analysis showed that there is not significant difference between all group test at weeks 3 than week 6 . This result could because the difference of the induction and therapy with the previous studies. High carbohydrate diet and fraction test gave at the same time until 6 weeks so assumed that pancreas of the animal test in induction group could able to compensate or modulate the changing of blood glucose level in the body.

All test animals were sacrificed at the end of therapy. The organ cardiac, liver, renal fat, and were isolated. Index of heart conducted to determine the structural changes of the heart due to the workload of the heart, index of liver to determine the presence of fatty deposits in the liver as a result of induction, while the index of renal fat and to determine body composition changes that affect the weight of test animals.

Based on the Fig. 9 had known that the group has an index of liver acarbose highest compared with other groups; meanwhile, the water fraction group at doses $65 \mathrm{mg} \mathrm{kg} \mathrm{bw}$ has an index of renal fat and fat anal biggest compared with other test groups. Statistical analysis showed no significant differences in cardiac index, heart, renal fat, and fat anal among all groups. This result gave illustrates that there are differences in body composition between test groups so that even animal weighing induction group showed the greatest value compared with other test groups but has an index of liver, fat anal, renal fat, and a smaller than normal group and the test preparation. Body composition is the sum of all the parts of the body that consists of adipose tissue and fat-free mass (water, muscle, bone, connective tissue, and organ).
Body composition was measured to obtain the percentage of fat, bone, water, and muscle in the body. This measurement is also intended to determine the potential estimates of obesity in the body.

\section{CONCLUSION}

In this study, demonstrated that the ethyl acetate fraction at doses $4.5 \mathrm{mg} / \mathrm{Kg}$ bw can inhibit of increased body weight highest than other test groups. The mechanism of action from this effect was presumably by decreased appetite. The study also showed that the ethyl acetate fraction at doses of $4.5 \mathrm{mg} / \mathrm{Kg}$ bw potential to decrease of total cholesterols level, and triglycerides' level greater than the other test groups, where increasing of these levels of blood biochemistry were closely related to the pathology of obesity.

\section{REFERENCES}

1. Dipiro JT, Talbert RL, Yee GC, Matzhe GR, Wells BG, Posey BG. Pharmacotherapy a Pathophysiologic Approach. $7^{\text {th }}$ ed. New York: Mc. Graw Hill; 2008. p. 2437-51.

2. Nguyen DM, El-Serag HB. The epidemiology of obesity. Gastroenterol Clin North Am 2011;39:1-7.

3. Sunyer FX. Why Drugs? Pharmacotheraphy of Obesity. Switzerland: Birkhauser Verlag; 2008.

4. Azman KF, Amom Z, Azlan A, Esa NM, Ali RM, Shah SM, et al. Antiobesity effect of Tamarindus indica L. pulp aquous extract in high fat diet-induced obese rats. J Nat Med 2011;66:333-42.

5. Kuru P. Tamarindus indica and its health related effects. Asian Pac J Trop Biomed 2014;4:751-7.

6. Finna S, Adnyana IK, Sukandar EY, Sukrasno S, Yuniarto A, Pebritrinasari R. Pharmacological screening for potency of antiobesity on five plants based on ethnopharmacological use. Asian J Pharm Clin Res 2015;8:234-6.

7. Finna S, Adnyana IK, Sukandar EY, Sukrasno S. Activity of Tamarindus indica pulp water extract in high carbohydrate diets as antiobesity. J Chin Pharm Sci 2016;25:829-97.

8. Iftekhar AS, Rayhan I, Quadir MA, Akhteruzzaman S, Hasnat A. Effect of Tamarindus indica fruits on blood pressure and lipidprofile in human model: An in vivo approach. Pak J Pharm Sci 2006;19:125-9.

9. Iswanti DP, Kosim LD, Susanti A. In vitro pancreatic lipase inhibition by water and ethanol extract of Tamarindus indica and Kaempferia rotunda. Indones J Nat 2011;13:34-38.

10. Koyagura N, Hemanth V, Jamadar MG, Huilgol S, Nayaka N, Yendigeri SM, et al. Antidiabetic and hepatoprotective activities of Tamarindus indica fruit pulp in alloxan induced diabetic rats. Research Article. Int J Pharmacol Clin Sci 2013;2:33-40.

11. Martinello F, Soares SM, Franco JJ, Santos AC, Sugohara A, Garcia SB. Hypolipemic and antioxidant activities from Tamarindus indica L. pulp fruit extract in hypercholesterolemic hamsters. Food Chem Toxicol 2006;44:810-8.

12. Finna S, Adnyana IK, Sukandar EY, Sukrasno S, Pebritrinasari R. Animal Model of Obesity in Populations With Hight-Carbohydrate Diet. Kuala Lumpur, Malaysia: $12^{\text {th }}$ International Congress on Obesity; 2014. p. $17-20$

13. Wang T, Ma X, Peng D, Zhang R, Sun X, Chen M, et al. Effects of obesity related genetic variations on visceral and subcutaneous fat distribution in a Chinese population. Sci Rep 2016;6:20691.

14. Fajriaty I, Adnyana IK, Fidrianny I. Acute and sub-chronic (28 days) repeated oral toxicity test of ethanol extract (Sapindusrakak DC.) Fruits in wistar rats. Int J Pharm Pharm Sci 2014;6:487-92.

15. Gaesser GA. Carbohydrate quantity and quality in relation to body mass index. J Am Diet Assoc 2007;107:1768-80.

16. Fried SK, Rao SP. Sugars, hypertriglyceridemia, and cardiovascular disease. Am J Clin Nutr 2003;78:873S-880S

17. Park EJ, Hellerstein MK. Carbohydrate induced hypertriglyceridemia: Historical perspective and review of biological mechanism. Am J Clin Nutr 2000;71:412.

18. Raeni SM, Vanstone C, Papamandjaris A. Comparison of effect dietary fat retriction with that of energy retriction on human lipid metabolism. Am J Clin Nutr 2001;73:262-7.

19. Kalaiselvi P. Biochemistry. $1^{\text {st }}$ ed. Chennai: Tamil Nadu Textbook and Educational Services Corporation, University of Madras, Taramani Campus; 2005. p. 30, 74

20. Walker R, Whittlesea C. Clinical Pharmacy and Therapeutics. $5^{\text {th }}$ ed. Edinburgh: Churchill Livingstone; 2012. p. 389. 